Article

\title{
The New Global Urban Realm: Complex, Connected, Diffuse, and Diverse Social-Ecological Systems
}

Melissa R. McHale ${ }^{1, *}$, Steward T.A. Pickett ${ }^{2}$, Olga Barbosa ${ }^{3, \dagger}$, David N. Bunn ${ }^{4, \dagger}$

Mary L. Cadenasso ${ }^{5, \dagger}$, Daniel L. Childers ${ }^{6, \dagger}$, Meredith Gartin ${ }^{7, \dagger}$, George R. Hess ${ }^{1, \dagger}$, David M. Iwaniec ${ }^{7, \dagger}$, Timon McPhearson ${ }^{8, \dagger}$, M. Nils Peterson ${ }^{1, \dagger}$, Alexandria K. Poole ${ }^{9, \dagger}$, Louie Rivers, III ${ }^{1, \dagger}$, Shade T. Shutters ${ }^{10, \dagger}$ and Weiqi Zhou ${ }^{11, \uparrow}$

1 Department of Forestry \& Environmental Resources, North Carolina State University, Campus Box 8008, Raleigh, NC 27695-8008, USA; E-Mails: george_hess@ncsu.edu (G.R.H.); nils_peterson@Ncsu.edu (M.N.P.); 1rivers@ncsu.edu (L.R.)

2 Cary Institute of Ecosystem Studies, 2801 Sharon Turnpike, Millbrook, NY 12545, USA;

E-Mail: picketts@caryinstitute.org

3 Instituto de Ciencias Ambientales y Evolutivas, Facultad de Ciencias, Universidad Austral de Chile, Valdivia, Chile; E-Mail: olga.barbosa@uach.cl

4 The Knowledge Hub for Rural Development, Wits Rural Facility, The University of the Witwatersrand, Private Bag X420, Acornhoek 1360, South Africa; E-Mail: davidnbunn@gmail.com

5 Department of Plant Sciences, University of California, Davis, CA 95616, USA;

E-Mail:mlcadenasso@ucdavis.edu

6 School of Sustainability, Arizona State University, Tempe, AZ 85287, USA;

E-Mail: dan.childers@asu.edu

7 Julie Ann Wrigley Global Institute of Sustainability, Arizona State University, Tempe, AZ 85287-5402, USA; E-Mails: meredith.gartin@asu.edu (M.G.); david.iwaniec@asu.edu (D.M.I.)

8 Tishman Environment and Design Center, The New School, 79 Fifth Ave, 16th Fl., New York, NY 10003, USA; E-Mail: timon.mcphearson@newschool.edu

9 Department of Politics, Philosophy and Legal Studies, Elizabethtown College, Elizabethtown, PA 17022-2298 USA; E-Mail: poolea@etown.edu

10 Global Security Initiative, Arizona State University, P.O. Box 878409, Tempe, AZ 85287-8409, USA; E-Mail: sshutte@asu.edu

11 Center for Eco-Environmental Sciences, Chinese Academy of Sciences, Haidian District, Beijing 100085, China; E-Mail: wzhou@rcees.ac.cn

$\dagger$ These authors contributed equally to this work.

* Author to whom correspondence should be addressed; E-Mail: mrmchale@ncsu.edu; Tel.: +1-919-515-7579. 
Academic Editor: Marc A. Rosen

Received: 12 January 2015 / Accepted: 10 April 2015 / Published: 28 April 2015

\begin{abstract}
Urbanization continues to be a transformative process globally, affecting ecosystem integrity and the health and well being of people around the world. Although cities tend to be centers for both the production and consumption of goods and services that degrade natural environments, there is also evidence that urban ecosystems can play a positive role in sustainability efforts. Despite the fact that most of the urbanization is now occurring in the developing countries of the Global South, much of what we know about urban ecosystems has been developed from studying cities in the United States and across Europe. We propose a conceptual framework to broaden the development of urban ecological research and its application to sustainability. Our framework describes four key contemporary urban features that should be accounted for in any attempt to build a unified theory of cities that contributes to urban sustainability efforts. We evaluated a range of examples from cities around the world, highlighting how urban areas are complex, connected, diffuse and diverse and what these interconnected features mean for the study of urban ecosystems and sustainability.
\end{abstract}

Keywords: urbanization; urban theory; science of cities; socio-ecological systems

\title{
1. Introduction
}

In the age of the Anthropocene, researchers studying urban systems no longer have to justify their work with introductory statements reminding readers that we live in an urban world. Indeed, as an increasing number of urbanites consume more resources with every incremental step up in socio-economic status, scientists are striving to develop a unified theory of cities that can guide sustainability globally. Such attempts, however, are constrained by an urban ecological science that has developed largely within institutions, urban systems, and theoretical contexts of the Global North, whereas the most massive contemporary changes in the world's cities are emerging in the "developing" regions of the Global South [1]. Asia, Africa, and Latin America are the seats of the largest shifts in urban population, urban agglomeration, and urban form [2].

In this paper, we encourage ecologists, sustainability researchers, and practitioners to share in a broader conceptualization of urban systems to account for contemporary urbanization processes around the world. Greater appreciation of contemporary urban features, including the rapid and complex ways urban areas and their component parts are changing across space and time, should help interdisciplinary urban scientists pose new research questions, frame comparisons, and apply their knowledge to a broad range of urban sustainability issues.

Our specific objectives are to (1) synthesize four widely recognized urban features that capture the breadth of urban status and change; (2) demonstrate how awareness of these features can inform and broaden research efforts; and (3) evaluate how accounting for these features will help scientists 
advance a more integrative understanding of what constitutes sustainable urban systems. We build our framework on a foundation laid by problematizing current conceptions of urbanization and then elaborate on the four interconnected urban features using examples from various countries. These features are the "facts on the ground" that urban science must be better prepared to address. This framework links current models for classifying cities and suggests that there is a need to move beyond categorizing places based only on past and present function or basic landscape patterns. We present research questions to illustrate the intellectual flexibility of our framework, and a summary of what these features suggest about the promotion of urban sustainability across the globally rich array of urban systems.

\subsection{Four Urban Features: Complexity, Connectedness, Diffuseness, and Diversity}

There are a variety of useful and compelling, but disconnected, models of urbanization and urban change (Box 1). Each has a specific scope that may be seen as a part of a larger urban framework. We identify four attributes or features of urban systems that may cut across the many perspectives represented by the various urban theories and models. The four features of contemporary urbanization identified in this paper-complexity, connectedness, diffuseness, and diversity - are intertwined strands of urbanization. Sometimes these strands blend with one another, as these features can have similar implications. It is also important to note that complexity, connectedness, diffuseness, and diversity are obviously not the only characteristics that can describe cities, towns, and the processes of urbanization globally. This conceptual framework is inclusive, rather than exclusive, and many variables can be placed within its boundaries. In calling attention to these four features our intention is to broadly encompass the concerns of the many theories and models we have encountered (Figure 1). Essentially, we are motivated to create a platform for better incorporating urban ecological science (Box 2) into sustainability studies that can guide interdisciplinary and international research that is comparative. Globally relevant comparisons will be a foundation for a unified theory of cities that, arguably, does not yet exist despite claims to the contrary.

Complexity describes the spatially heterogeneous mosaics comprising specific cities or urban regions (sensu [3]) that are a result of urbanization and subsequent processes of growth, shrinkage, and change that occur within these mosaics. Both form and processes exhibit spatial heterogeneity, as do biological and social-economic-political phenomena. Thus, urban systems as both biophysical entities and lived qualities are spatially complex [4].

Understanding such complexity requires linking pattern and process at multiple spatial scales and preferably at a high spatial resolution [5], while acknowledging that there are both growing and shrinking cities and urban regions. Connectedness refers to the flows of energy, financial resources, influences, information, and materials across spatially complex mosaics, as well as through social dynamics occurring across complex networks. Connectedness also encompasses the flows and teleconnections among urban regions and other landscapes across the globe. Diffuseness alludes to the porosity of social and biophysical boundaries around cities, suburbs, exurban nodes, and their associated rural and wild lands. Diffuseness also points to mechanisms of connectivity, including overlapping governance arrangements, distributed social and institutional structures, and the almost instantaneous flow of information between geographically distant points. Diversity alerts researchers to the wide variety of structural and functional models that apply across urban systems. Diversity 
across different cities and urban systems includes the nature of urban form and fabric, infrastructural arrangements, human densities, economic activities, cultural demographics, biotic species, lifestyles, and livelihoods. The diversity of urban systems across the globe is already large, and may increase as urbanization spreads to new regions. A framework accounting for complexity, connectedness, diffuseness, and diversity positions urban ecological science to pursue international comparisons that allow for the development and testing of global generalizations and, at the same time, encourages place-specific relevance.

\subsection{Problematizing Urbanization: Succession and the Process of Change}

The first step in developing a useful framework to account for the richness of urban regions and the new combinations of urban conditions that exist or are emerging around the world is to "problematize" [6] urbanization. Problematization is an analytic strategy in which familiar knowledge or beliefs are examined critically; underlying assumptions and the epistemology are re-examined, and "facts" challenged. In ecology, for example, urbanization is often narrowly conceived as a process that converts wild lands or lands that are used to supply natural resources to lands devoted to dense human settlements and industrial processes [4].

Recognizing the limits of the conversion model of urbanization is the first step in problematizing the concept of urbanization. It suggests a one-way transition of structure and function, and says little about the subsequent changes that exist within residential, commercial, and industrial settlements. In northern Europe and North America, urbanization has often been linked with industrialization and the associated transformation of settlements from centers of commodity collection and trade, to water and then fossil fuel powered industrial systems, to sanitary or hygienic cities [7-9]. These simple and unidirectional explanations are brought into question, for example, by the recognition of post-industrial urban change [10], the processes of urban abandonment common in the Global North [11], or by the existence of cities in the Global South that have flourished in the absence of an industrial phase, and are growing now as centers of consumption or other services [12-14].

Researchers studying the historical development of the world's cities have similarly questioned the misguided assumptions that underpin a deterministic model of the evolution of cities. Archeologists are questioning this idea of a "typical city" and suggest that an understanding of urban dynamics requires a more localized approach accounting for the variability that exists across cities through time [15]. Perhaps like the ecological process of succession — which has come to be viewed as an open-ended process rather than an inevitable progression toward a stable, metabolically equilibrated community $[16,17]$ — urbanization can be productively viewed as a continual and dynamic process rather than an inevitable progression toward an industrially or consumer-based structure. It may be useful to think of urbanization, like the contemporary theory of succession [18] as a process that is nonteleological and hence has no inherent endpoint or perfectly achieved stable state. Of course, one might be hesitant to consider urbanization in an successional context, as the Chicago School has been criticized for promoting similar motivations; however, we are not talking about the old mode of understanding succession as a linear process as was done in the 1920s and 1930s [19]. Instead, the contemporary vision of succession focuses on non-linearity and adaptive processes. The result of this new emphasis across 
disciplines will be to understand the patterns, causes, and perpetuity of change, the origins of novelty, and the implications of process and transformation.

\section{A Framework for Global Urban Change}

Complexity, connectedness, diffuseness, and diversity are already well recognized in different discourses associated with disparate disciplines addressing the cities [1,20-22]. We bring them together in our framework to benefit urban research and the application of science to the practical problem of improving the social and biophysical environments of cities, suburbs, exurbs, and the other lands with which they are connected (Figure 1, Box 2). Below, we describe four features of urbanizing regions while referencing observable instances in which they are manifest around the world.

\subsection{Complexity}

Complexity refers to the variety and configuration of components and processes within an urban system, whether it be a city or an urban region. For most of their history, cities have been distinct, though not disconnected, from their hinterlands [23]. Even a "suburb" was originally an extra-urban settlement outside the walls of Medieval hill towns, and the abode of those excluded from formal citizenship and full-time participation in the life of the city enclosed within the walls. Suburbanites would often be locked out of the city when the gates closed at night. From the Enlightenment, through the early industrial revolution, and into the Romantic and Modernist periods, Euro-American philosophical understanding became focused on the idea of the city as a place of both triumph and alienating loss $[23,24]$.

Box 1. Theories and Models of Urbanization.

There have been a plethora of theories developed to capture and explain cities. Below we briefly describe an assortment of the models developed to explain or understand urbanization. We aim to exemplify the scope of urban models addressing form and function, and do not intend to present an exhaustive list. Although the models depict a diversity of interests and perspectives, there has not yet been a unified theory developed that encapsulates the four global urban features.

\section{Biophysical Models}

- A Power Law of Urban Size [25]. The population of urban areas is statistically related to urban characteristics. Innovation, crime, infrastructure, and wealth, for example, have been shown to increase nonlinearly with increasing city population. Economies of scale are associated with the infrastructural features, while socio-economic outputs, such as wealth, are enhanced by the diversity and intensity of social links and display superlinear growth relative to city size [26].

- Urban Form [27]. Classical city theory notes a progression from city design that embodies cosmological significance as ceremonial and administrative centers, through industrial production, and finally to a sprawling form growing by incremental and financially driven additions. 
Box 1. Cont.

- Street Networks [28]. Proposed that the open grid familiar in cities driven by colonial expansion and industrial and business growth, has shifted to a cul-de-sac or pinnate form with its associated focus on enclaves. Marshall [29] concentrated on the needs of transport and the rank hierarchy of streets. He proposed a three-dimensional analyses for comparing road networks. More recently, Strano et al. [30] suggested that the long-term evolution of road networks can be modeled more fundamentally as emerging from the interplay between innovation and increased density.

- Block Form [31]. City block forms are related to street form, but taking an alternative perspective, are used to classify cities into four kinds based on the distribution of sizes and shapes of their blocks.

- City Patch Types [32]. Following on the ideas of Foucault [33], Shane [32] has proposed that cities be seen as a changing array of patch types. He identified armatures, or connecting features, with enclaves of particular use or structure, and heterotopias, that is enclaves of creativity, novelty, or experimentation in the urban fabric. Heterotopias may be cryptic, as in those focusing on socially marginal groups or behaviors, or conspicuous as in the case of schools or artistic establishments.

- City Function [34]. In the early 20th century, U.S. cities could be classified into nine main types. Aside from the inevitable "mixed" or diversified category, there were manufacturing, wholesale, educational, retail, transportation, resort and retirement, mining, and capitol centers. A simple ecological perspective has used such functions to focus on commodities and trade, housing of refugees, industrial manufacturing, sanitation and hygiene, convenience, consumption and entertainment, and sustainability as "modes" of urban form and function [35]. An entire city may be labeled as one of these types or, more likely, comprise locations that express different functions.

- Infrastructure Theory [8]. Although the ecosystem concept would seem adequate to represent the components, interactions, and dynamics of built, social, biological, and physical aspects of cities, interest in infrastructure particularizes these concerns. The subsystems of urban regions are often referred to as green, blue, and grey infrastructures. Specific instances are transportation, water delivery, stormwater removal, energy, and waste removal systems and networks [8,36-38], with biophysical infrastructures exemplified by parks, street and yard trees, and biodiversity. A related conceptualization of the components of urban systems is as social, human, built, financial, and natural capitals. The human ecosystem framework is yet another representation of the subsystems of cities, suburbs, and exurbs comprising complex urban regions [39]. 
Box 1. Cont.

\section{Social and Political Models}

- Place as Lived Space [40]: The biophysical models listed above often emphasize the material and formal nature of urban systems. Henri Lefebvre's The Production of Space [40] argues that cities are much more than abstract spaces, commoditized and governed from the top down. His theory serves as a transition to several examples, below, that theorize urban systems based on people's perceptions, actions, needs, social adjustments, and institutional arrangement. Cities, as Marcotullio and Solecki [4] note are both physical quantities that are mapable and measurable, but they are also human and social qualities that affect people's sense of self, place, and well-being and which govern their interactions with one another and with their built, biological, and mediated environments.

- The Human Ecosystem Framework [39]. Not a theory per se, but a hierarchy of potential causes and interactions that can occur in urban systems, the human ecosystem framework includes attributes reflecting both biological and social (in the largest sense) origins and interactions. It acknowledges that urban systems are founded on fundamental biological and ecosystem processes, which have come to be grouped as ecosystem services [41]. However, it also notes the necessity of resources such as the myths, organizations, and beliefs a culture provides. It also includes socio-economic resources, such as information, human population, labor, and various forms of capital. These biological and socio-economic resources are accessed, allocated, and used by a social system, embodying institutions, social ordering mechanisms, and temporal cycles or changes.

- Political Ecology [42,43]. A theoretical approach to understanding how struggle and conflict determine the relationships of people with the environment. Political ecology explicitly acknowledges that social and spatial dynamics in urban systems are contested, and that there arise a variety of networks and institutions, both formal and informal, to operate in contested fields of action. Race, class, and ethnicity are common determinants of access to power. Political ecology can also be considered a normative and practical approach to power relations in urban systems.

- Economics of Locational Choice [44,45]. The fundamentals of economics suggest that people have perfect knowledge, access to capital, and freedom to choose where to locate if they have sufficient capital, have motivated such things as bid rent theory. Potential purchasers, such as firms or households, can make trade offs concerning the size of parcel purchased versus the location of that parcel relative to urban amenities. Theoretical advances have added understanding of the constraints on knowledge, access, and freedom, and have acknowledged that in any locational choice there will also be a trade off that may involve non-monetary "push and pull" factors. 
Box 1. Cont.

- Culture and Symbolism [46,47]. This view of urban areas is founded on the cultural and semiotic determination of urban form and activities. It accommodates both individual behaviors and shared group identity. Recent expansions into theories and models of consumption, such as an "ecology of prestige" [48] for explaining purchasing and maintenance behaviors within and between neighborhoods, is an example of this category of urban theory.

- Industrial Capitalism and its Discontents [49,50]. The rise of capitalism and of cities is seen as entangled. Cities can be seen as growth or production "machines," in which part of the production is of labor itself, either by birth in situ or via migration and the conversion of farmers to wage workers. Generation of the middle class, as distinct from the working class, and the associated development of middle class suburbs are phenomena addressed by this theoretical realm. Of course, critiques of the viability of cities as capitalist institutions have existed since Marx and Engels [51].

- Globalization [52]. Cities are increasingly seen as nodes in global financial, production, and commercial networks. Perhaps correctly thought of as emerging from the centuries-old European and Middle Eastern colonial enterprises, globalization now involves virtually instantaneous transfers of information, capital, persons, and to a slightly lesser extent, raw materials and consumer goods. The position of cities in global networks not only affects their relationships with their peer cities around the world, but also shapes their regional and local connections.

- Polycentric Governance [53,54]. With the change of cities from relatively focused metropolises, to linear megalopolises, and finally to urban mega-regions (or megacity regions), the spatial scaling of government has become mismatched with the effective urban scale. Hence, governance takes on informal, corporate, and cross-boundary attributes. Public-private partnerships have emerged as a familiar tactic in polycentric regions, as have quasi-governmental authorities. Concepts such as "the rights to the city" and privatized public space become important under this theoretical perspective.

- Social Heterogeneity and Innovation [55,56]. Classical urban social theory notes that urban areas are socially diverse, bringing together persons of different ethnicities, traditions, religions, ages, genders, and intellectual backgrounds. Such heterogeneity can spark conflict, such as that studied under Political Ecology, but it fundamentally also generates novelty and innovation. The role of innovation and creativity founded on density, mixed access, and informal venues for interaction is a powerful factor employed in some urban theories.

Countervailing, anti-capitalist forms of central planning in the USSR and China tried to combat this determining nostalgia, arguing instead for the necessary process of urbanization and the inevitable emergence of history's true actors: the urban proletariat class. Even during the early 20th century, residents and scholars noted the sharp boundaries between city and countryside, in which a housing development gave way to extensive and continuous agricultural or wild lands outside the city. This level of distinction is becoming rare, however, since the blossoming of the fossil-fuel-powered era. Especially after World War II in the Northern Hemisphere, cities and their rural and wild surroundings, while still visually apparent, have become less distinguishable in many other ways from their rural or 
wild surroundings. More recently, technological change, particularly in the form of the Internet, and post-Fordist production processes, have increased social and spatial fragmentation and accelerated the blurring of distinctions between what is urban, suburban, and exurban [12,57-60].

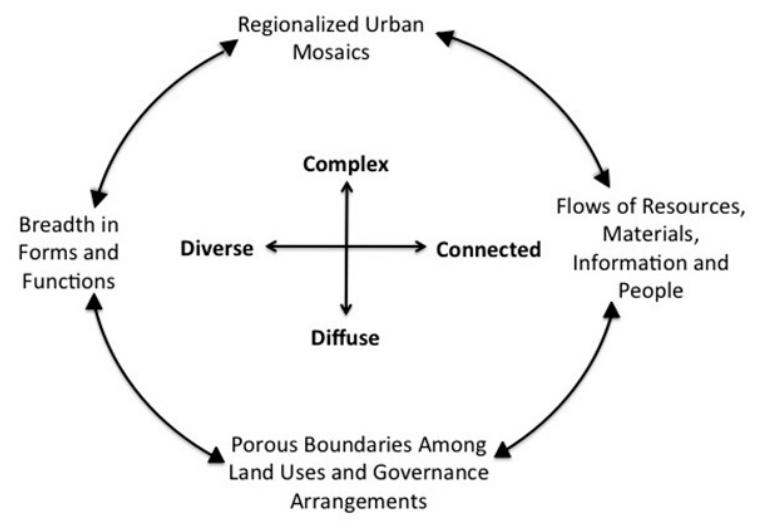

Figure 1. A framework representing the features associated with global urban change. Urbanizing areas around the world can be characterized as complex, connected, diffuse, and diverse. These four global urban features can serve as a platform for the development of interdisciplinary research on the urbanization process that is comparative and globally relevant.

Cities have never been functionally isolated from the hinterlands on which they depend for ecological production and waste processing [61,62]. However, with the expansion of motorized transport, the rise of a middle class suburban ideal, and suburb-friendly government policies in the United States, for example, cities became part of larger urbanized regions in which various land uses were comingled [13]. Gottmann [63] was the first to identify this phenomenon, describing the northeastern seaboard of the United States as a "megalopolis." Since then, as urban regional systems have continued to change around the world, they have been spoken of as "agglomerations" and more recently as "megaregions" [64,65]. Importantly, such spatially complex aggregations include not only densely populated and densely built centers, but also suburbs, commercial nodes, transportation corridors, business and industrial parks, innovation campuses, and even interdigitated wild and rural lands [66].

Such regionalized urbanization patterns exist around the world. Ironically, megacity regions may be difficult for citizens and policy makers to visualize readily [53]. The Regional Plan Association [67] identifies eleven urban megaregions in the United States, and projects their spatial expansion through 2050. In China, official policy calls for the development of 23 urban megaregions [68]. Many of these are already in place with megacities as their main structural nodes [69]. Europe also possesses urban megaregions, the most famous being the swath of cities and exurban development stretching from England to Northern Italy [70]. In Latin America, megaregions have emerged as a recent urban expression, through the interaction of metropolitan areas with secondary cities such as the case of Sao Paulo, Campinas, and la Baixada Santista, constituting the strongest industrial and economic force of Brazil with 26 million residents [71]. Traditionally, industry has powered the urban cores, but agriculture is well represented within the region. The central idea, which is now commonly exemplified across continents, is that urbanization and urban processes encompass and involve large regions [72]. Urban areas now constitute complexes of regional extent. Regionalization of urban processes, a key feature of complexity, serves as a driver for many of the characteristics associated with the other three urban features. 
Box 2. Urban Ecology_-Potential Contributions for Advancing the Science and Practice of Urban Sustainability.

- Heterogeneity [73,74]. Cities and towns are structurally heterogeneous. Previously utilized methods for characterizing structure at large scales were not refined enough to capture the heterogeneous nature of urban locales. For instance, urbanization at large scales is usually quantified using low-resolution (30 m or greater) satellite imagery. Although these methods are useful for displaying general urbanization processes, they can only indicate broad differences among developed and undeveloped land areas

- Pattern and Process [75-77]. Quantifying heterogeneity in the biophysical environment is extremely important because landscape patterns are inextricably linked to ecological processes. Ecologists often also refer to this as a relationship between ecosystem structure and function. Although the study of these linkages has a long history in ecology, landscape and urban ecologists are advancing these concepts utilizing studies of heterogeneous urban systems.

- Social-Ecological Systems [78-80]. When studying urban systems there is a need to address the social part of the system as well as the ecological. This calls for interdisciplinary science to address sustainability issues and has led to numerous conceptual frameworks for studying complex and integrated social-ecological system.

- Ecology of Cities [78,81]. Early urban ecologists tended to do "ecology in the city." However, as the field of urban ecology developed ecologists there became a need to do more work on the "ecology of cities." Only by studying cities in a comparative way can scientists understand the drivers of development and the impacts of urbanization over the long-term [82].

- Patch Dynamics $[9,83]$. The spatial heterogeneity of urban systems can be expressed as social and as biophysical patches. However, such patches are connected by various flows and influences, and are capable of changing size, shape, and spatial configuration. The changes can be driven by internal processes and externally originating phenomena. Hence, patch mosaics are dynamic in both space and time, and provide a useful approach for understanding urban form and change. The "metacity" concept is an outgrowth of patch dynamics applied to urban areas as social-ecological systems.

- Continuum of Urbanity [1,84]. This concept distills the idea that urban and rural can no longer be considered to be discrete systems. Rather, most areas on Earth are now some combination of urban and rural attributes and processes. The continuum of urbanity thus acknowledges a gradation of these formerly different kinds of system based on dimensions of livelihood, lifestyle, regional and global connectivity, and the effects of these three phenomena on the social and biophysical environments of specific places.

- Urban Ecological Resilience [35]. An adaptive cycle of resilience, emphasizing the ability of systems to adapt and respond to internal and external shocks without collapsing, has been a guiding theory for natural resource management [85]. Its translation to social-ecological systems in general has invited exploration of its applicability to urban systems. Still in its infancy, urban ecological resilience provides an alternative to the traditional engineering resilience theory, which often assumes an equilibrium reference point, deterministic dynamics, and the predominance of resistance rather than adaptation to change. This concept provides links with urban design and sustainability planning [86]. 
Box 2. Cont.

- Biogeochemistry and Energy Flux [87,88]. A powerful research tradition in ecosystem ecology is the mass balance approach for understanding the fluxes and control of nutrients and contaminants, and the fluxes of useful and waste energy. In the urban realm, following traditions from the social sciences, such studies are often labeled "metabolism" [89]. Of course the flows of matter, contaminants, and energy in urban ecosystems are linked to economics, power, politics, institutional structures, human capital, and social capital [39].

Overlaying these emerging, complex spatial patterns of globalization is a cultural mosaic of characteristics - beliefs, norms, institutions, and governance regimes - that interacts with the geospatial mosaic to create a richly diverse socio-ecological landscape in which urbanization occurs [90]. The interplay between these overlapping mosaics has profound implications for prospects of sustainability [91,92]. Taken together, along with a mosaic of information flow, innovation transmission, and associated feedbacks, Samet [93] asserts that tools and methodologies from complexity science will be integral to the emergence of a true science of cities. Such flows characterize the next major urban feature.

\subsection{Connectedness}

Connectivity within and among urban regions is another major global feature that urban ecological research and its application to sustainability must address. While the movement of resources and wastes has been a conspicuous part of all urban regions since the beginning of civilization, the kinds and intensities of connections have increased greatly during the contemporary era [20,94]. There are now masses of materials, energy, and information moving through urban cores, suburban neighborhoods, and commercial and industrial establishments. Migration within urban regions, as from core cities to suburbs and exurbs, and the associated intensification of commuter flows, is now common. However, the inter-urban connectivity patterns of migrations and resource flows strongly affect the growth or collapse of cities [95]. North Carolina's Research Triangle is an exemplary model of these commuter movements across space; with members of the same household employed in different cities, at least one individual is often traveling to a neighboring town for work [96]. In addition, the directionality of commuting has become more complex as people travel between suburbs and exurbs for work, rather than primarily to and from a central metropolis [97,98]. Telecommuting, in which people work remotely from home, facilitated by the Internet, has added a novel dimension to connectivity within urban regions.

At medium scales, the connections in urban regions often link land types that had previously been considered disjunct in space and distinct in functionality. Former city-dwellers, whose lifestyles reflect narrowly defined urban sensibilities, migrate to new homes on rural properties that abut woods, fields, and streams [66]. With little appreciation for the benefits or risks associated with proximity to these environments, they suddenly experience - and frequently demand official interventions to mitigate — hazards including large animals and wildfire [99].

At coarse scales, familial ties now link people who were initially a part of the same localized household, across multiple urban regions or across both urban and rural territories. These families are still intricately connected, often through financial transactions in the form of remittances. The result is 
a "distributed household" that had previously been thought of as distinctly rural or distinctly urban. In parts of Africa and Asia in particular, a single address, whether in a nominal city or the official countryside, no longer identifies a person or a household. Indeed, a distributed household may have active participants in a dense village and distant cities [100]. Further complicating our understanding of households are the complex migration patterns now seen in many parts of the world. Such patterns can be bidirectional or even circular, with household members moving based on the needs and opportunities of different seasons or different life stages [101,102]. These connections across large distances reflect the opportunities and constraints of both livelihood and lifestyle $[1,84]$.

The connectivity of urban systems extends to the global scale. Remittances from city jobs to rural locations, even between continents, affect the social and environmental structures of the receiving places. There are many cases in Latin America, Africa, or Asia where remittances are crucial and longdistance connections exist between different densities and styles of settlement [103,104]. In Africa, for example, areas that are considered rural have a demographic structure that reflects the absence of young adults and middle-aged persons who are engaged in permanent or temporary work at a great distance [102]. Examples of inter-continental connectivity also exist. People who live primarily in temperate regions also often own vacation homes in distant Mediterranean or tropical areas, which subsequently de-emphasize agriculture to meet demand for vacation homes [105]. Paradoxically, entire regions of the developing world may find themselves having to service the idealistic needs of a global tourist industry focused on utopian notions of picturesque, rural peasant cultures [106]. In the process, the affected rural areas become less agrarian and shift to service economies [103]. Greater connectivity can also influence behavior. For example, shifts in diet as Asian economies support a more carnivorous middle class affect forests and fields in Australia and the Americas [105,107,108]. Rural areas connected to these distant urban systems are altered for animal husbandry or to grow grain to support animals, with accompanying shifts of forest cover and of human and wildlife migrations in the source continents. Burgeoning consumer demands for prestige goods and energy in China or Russia led to waves of poaching of rare animals in Africa or Latin America, or the conversion of communal lands to grain or biofuel production for offshore needs.

Such distant connections are often referred to as "teleconnections," and are already massive and increasing as the processes of globalization and urbanization intersect [20]. Vitally important to the effectiveness of long-distance connections are various electronic media controlled by individual users [109]. The Internet, social media websites, and mobile phones quickly spread information, instructions, political campaigns, and even financial resources. Mobile phone-based banking in Africa exemplifies that many important interactions no longer require the exchange of physical materials or currency.

This global connectivity among urban regions has led to the emergence of global city network research [110,111]. Such global city networks have topological properties and dynamics unique to the global scale [112] and, similar to metapopulations [113,114] and patch dynamics [83] in ecology, have a strong influence on local urban dynamics of cities within the network (Box 2). Network dynamics and influence on individual cities are important components of a framework for a new ecologically relevant science of cities. Thus, a global perspective of cities takes into account the larger dynamics that influence both environmental and cultural inputs at local scales, as well as the global inputs to explain the extent to which urban areas homogenize or vary. 


\subsection{Diffuseness}

Diffuseness refers to the porous boundaries within and among urban regions. Connectivity is enhanced by diffuseness because different kinds of habitats, neighborhoods, or land uses are no longer separated by long travel times or large distances; and species, materials, people, and resources flow quickly within urban regions. Connectivity is also facilitated by the distribution of similar social structures across contrasting spatial units. Consequently, the physical boundaries that still exist often become less impenetrable than they were previously. Families in distributed households share resources, lines of filial responsibility, and modes of dispute resolution across geographic or jurisdictional boundaries. Distribution of households has socio-environmental implications as well, including increased resource consumption for replicate infrastructure, reduced commitment to local environmental quality, or a decrease in local social capital [115-117].

Within urban geography and cultural anthropology, contemporary conceptions of diffuse urban identity depend strongly on the idea of transnational "flows." For Manuel Castells [118] and Arjun Appadurai [119], modern economies are disjunctive and placeless, with the world of goods and the circulation of commodities determining cultural landscapes between cities in an increasingly common international urban culture.

An important form of diffuseness is the nature of governance in spatially complex and extensive urban regions. Urban agglomerations have spread beyond old city boundaries, and even countybounded metropolitan government is sometimes too small to bring an entire city-suburban-exurban system within its authority [117]. Governance - the process of setting and enforcing formal norms and arranging for shared benefits and mechanisms of financial and social support—no longer matches the scale of government. In the United States, formerly discrete metropolises located within a single state have become parts of spatial and social structures that cross state boundaries, and in some cases international boundaries [67]. Inter-state authorities or compacts have been formed to address transportation and environmental challenges. The Port Authority of New York and New Jersey, the Bay Area Regional Transit in California, and the Chesapeake Bay Program are examples. The Chesapeake Bay Program addresses water quality issues in a 64,000 square mile watershed that encompasses the District of Columbia and parts of six states. Initiatives to mitigate the impairment of water quality in the Chesapeake Bay spread resources, responsibilities, and accountability across states. Similar compacts also exist internationally. For example, the Greater Limpopo Transfrontier Conservation Area extends across the borders separating the African countries of Zimbabwe, South Africa, and Mozambique. Treaty arrangements, issues of game management, control of poaching, and the relationships to communities abutting the constituent national parks and private game reserves are aspects of governance that emerge from this international compact [120-122]. In a model that is becoming increasingly common internationally, those who live in these transfrontier zones are no longer citizens with rights in a nation state, but residents subject to the whims of international conservation organizations [123].

Diffuseness expressed by governance arrangements also encompasses various sectors. The formal governance by local, state, and federal entities are complemented by private investment and decision making, and the investments and decisions managed by non-governmental organizations and community groups [124]. There are different degrees of accountability, transparency, and spatial scope represented within this mixture of sectors and the resources upon which different actors draw. Diffuseness thus 
stretches across spatial scales and hierarchical levels, spatial extent, and sectors of social organization. The diffuse nature of new modes of decision-making is evident in South Africa's development of a new level of governance at the watershed scale — catchment management agencies. This polycentric government arrangement was initiated to more equitably manage limited water resources and fully account for the needs of diverse actors within each watershed.

\subsection{Diversity}

Diversity emphasizes the differences among urban systems globally. Our conception is different from the diversity or social heterogeneity within cities long recognized by social scientists [55]. Diversity among urban regions reflects the various vintages, histories, motivations, and forms of urbanization [21]. It also reflects the different kinds and degrees of complexity, connectedness, and diffuseness in different urban regions, and the context dependent nature of emergent patterns [125].

Harris [34] created one of the earliest classification systems for the functions of cities in the United States. He identified nine types, including such categories as manufacturing, retail, educational, and resort centers. Cities and urban regions have evolved since this initial classification scheme and their functions altered by the emergence of service economies and lifestyles of consumption. Indeed, some geographers and anthropologists have identified cities of convenience and of consumption as new entries in the lexicon of global urban diversity [126,127]. The shrinking city is also a novel class in which infrastructure, such as modes of production and transportation built for large, but now dwindling populations, is no longer well matched to current needs [11]. Examples exist in the so-called "rust belt" of the northeastern and Midwestern U.S. and in eastern Germany. For Neil Smith and others [128], the withering away of the urban core extends to key suburban areas as well, in what has been termed the "Camden syndrome".

Perhaps the greatest contribution to diversity in urban form is emerging in Asia, Africa, and South America. In these locations, vast self-built, poorly governed districts are appearing. Variously called shantytowns, favelas, or the "slums," they represent dense neighborhoods often catering to recent or circular migrants, and are often poorly served by sanitary infrastructure and resource delivery systems $[14,129,130]$. In some cases such settlements are illegal and at best officially ignored; in other cases, they are subject to eviction and demolition with no allowance made for alternative habitation. In situations where the spread of dense, contemporary urban building engulfs existing rural villages, comparatively disadvantaged settlements become a part of the urban fabric [129]. Shantytowns [131], due to their opportunistic and unofficial status are frequently built on marginal lands such as floodplains [132] and steep slopes vulnerable to physical and anthropogenic disturbance. For example, during April 2014, 15 people died and nearly 2900 people lost their homes in the biggest fire recorded in Valparaiso, Chile's main port city. The fire was fueled by the proximity of houses to plantations of exotic fast-growing tree species, illegal trash dumps and an extremely steep geography that restricted access by emergency services [133]. Some shantytowns have been converted to permanent housing, and officially sanctioned by authorities irrespective of their haphazard locations or potential hazards.

While the state may choose to define vast informal settlements in terms of an older rhetoric aimed at crime or disease, "slum" megacities are in fact also sites for newly diverse kinds of experimentation with local governance by social movements [134-136]. Mumbai, for instance, provides a startling 
example of how widespread alliances between activist housing organizations amount to a new kind of emerging, urban democratic process increasingly linking shack dweller organizations globally [137].

At the other end of the spectrum, rapid urbanization can produce massive, dense, high-rise districts that remain under-populated and lack social functionality until urban migration catches up with the new housing and commercial building supply. In China, national and megacity policies almost certainly guarantee that such "ghost cities" will eventually be occupied, but they can remain underutilized for some time [129]. Moreover, the emergence of megacities (defined as urban areas supporting more than 10 million residents) is part of the developing diversity of urban types. Some megacities have reached well above that population threshold, and new categories, such as super city, have been proposed [138]. Other contributions to among-city diversity include emerging urban forms include the placement of factories in the countryside or in formerly agricultural villages. The use of old villages also shifts as they are folded into commuter orbits, or as owners or members of rural collectives move to newer urban districts but rent their homes to others. Physical layouts, uses of buildings and land, and demographics are part of the diversity of urban forms that go beyond the expectations of traditional models (Figure 2).

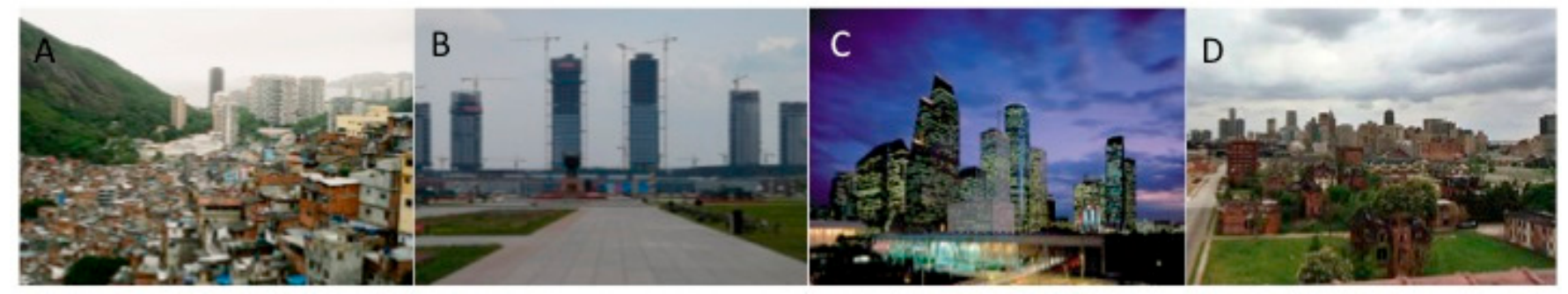

Figure 2. Global cities display a diversity of urban forms and functions. (A) From favelas in South America [139]; (B) to the new cities in China [140], there are various urban forms emerging around the globe that are in need of study. Similarly; $(\mathbf{C})$ cities of consumption like Houston [141] or (D) shrinking cities such as Detroit [142] provide context on the overall function of a city, and specifically can be analyzed to address the world's greatest sustainability challenges. All pictures are available in the Creative Commons.

\subsection{A Continuum of Urbanity}

The result of these four features of urban regions is that the rural and urban are intricately entangled in what Boone et al. [84] called "a continuum of urbanity." The concept might equally well be called an "urban-rural complex" or equated with a spatially extensive, patchy, and dynamic metacity (sensu [9]). Such entanglement is characterized by shifts in livelihood and lifestyle, and is driven by connectivity of regionally and globally dispersed places or ecosystems [1]. Further, this entanglement is very much related to the four features we have posited. Indeed, we identified these four kinds of urban features or facts on the ground based on the motivation of the continuum of urbanity [84] as a theoretical foundation. The spatial complexities of urban/rural mosaics, their connectivity at medium to global scales, the diffuseness of their physical, demographic, and institutional boundaries, and the resultant diversity of urban forms now emerging, all these have implications for both research and sustainability. 


\section{Research Implications}

The changing nature of urban regions considered through the lens of the four features, which we have identified from the various literatures of urbanism, suggests several avenues for future ecological research. Because the global foment of urban change requires urgent attention, urban social-ecological research must extend geographically beyond North America and Northern Europe, the birthplaces of contemporary urban ecology [143,144]. There are already impressive initiatives in China (Beijing Urban Ecosystem Research Station [145,146], and South Africa (African Centre for Cities [147], South African Environmental Observatory Network [148]). These, and similar programs in the Global North (e.g., U.S. urban Long-Term Ecological Research sites [149,150]; French Zones Ateliers), must be complemented by work in a much broader array of international locations-including comparative efforts among cities [151].

Expanded research on urban systems must be focused on multiple drivers of change. For example, do growing and shrinking cities respond similarly to the same driving factors, or do they require entirely different process models? What can we learn by studying places that are just now growing into cities? How do the processes and patterns evident as these places grow compare to the processes and patterns in extant cities? These questions confirm the need to focus jointly on pattern and process in urban research. The new patterns of urban-regional complexity must be measured rigorously, and hypotheses articulated carefully to address their joint social and ecological outcomes in diverse locations.

Open questions fundamental to future research include but are not limited to the following: Do we have an adequate roster of urban models? How many are needed? Can we base them on more than patterns, such as the different functions of U.S. cities identified in the 1940s [34] or the 13 types recognized in the Atlas of Cities [21]? How can ecologically relevant urban typologies address cities as both quantity and lived quality [4]? Are there emerging features of urban differentiation that escape being captured by the analytical criteria used in the past?

The familiar maps of urbanization that represent the spread of cities as a uniform patch type at coarse spatial scales clearly represent that process too simply (Figure 3, Box 2). There are several important criteria for new urban models: (1) they must go beyond land use; (2) they must encompass not only nominally urban or city cores, but also include what may seem to be rural settlements along with the fine scale structural complexity of entire urban regions; (3) these first two points suggest that regional models of urban systems must also incorporate an understanding of livelihoods and lifestyles, attitudes and beliefs, as well as more familiar basic demographics of populations; and (4) the multi-directional flows of commuters, migrants, materials, investments, and influences among the different spatial locations in the regional mosaics must be understood. In other words, bioecological processes must be better linked with politics and policy [43]. Sometimes a common currency may be used, while in other cases, causal entailments best described by narrative may be the starting point [152].

We know that governance systems are overlapping in extensive urban regions, but what do these structures mean for the ecological and social function of whole regions and their parts [153]? Governance structures take an extraordinary variety of forms. In some African urban regions, locally elected officials, traditional authorities, provincial government, national government, local and international non-governmental organizations are all part of the governance structure. However, it is often likely 
that local community or distributed household governance structures are not a part of decision-making processes concerning local or regional governance issues, such as assessments of ecosystem services. How such diffuse and mixed power and decision-making relationships are related to each other, and how each affects ecological processes and structures as well as social cohesion, social justice, and environmental justice are important questions.

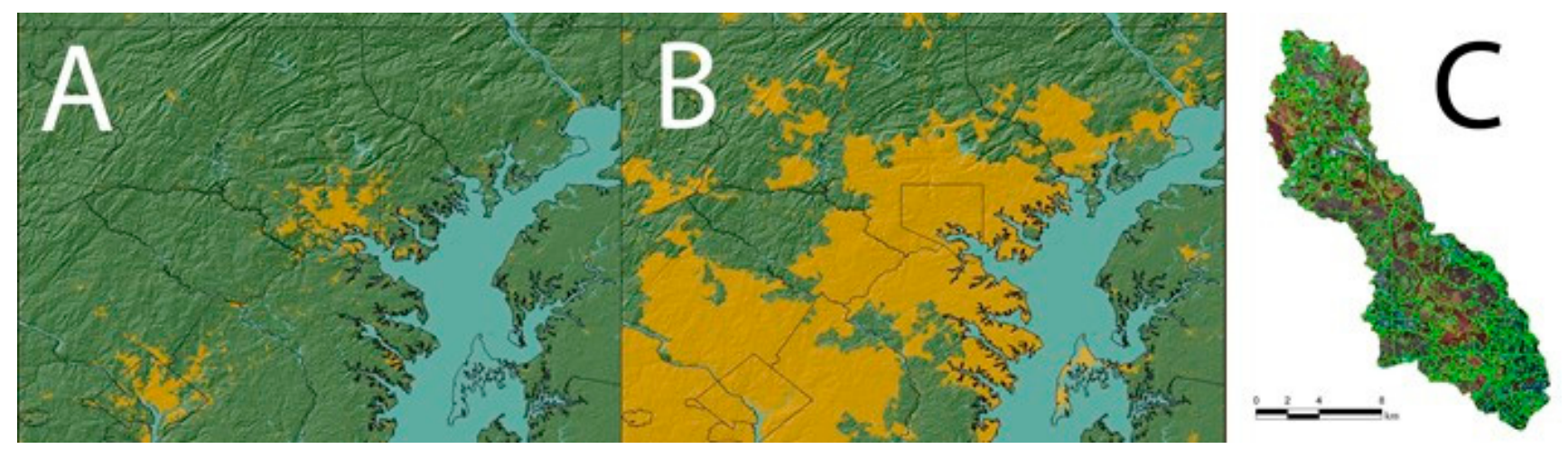

Figure 3. A coarse view of urbanization compared to a conceptually and spatially refined assessment of within-urban heterogeneity. (A) The Baltimore and Washington DC area in 1938, showing urban lands in dark yellow and non-urban lands in green; (B) The same area in 2001, showing urbanization as a coarse scale land conversion process; (C) A highly spatially and conceptually resolved classification of a $c a$. 17,000 ha watershed spanning between Baltimore City and Baltimore County using the HERCULES (High Ecological Resolution Classification for Urban Landscapes and Environmental Systems) classification (cf. [74]). All images courtesy of the Baltimore Ecosystem Study, LTER.

Consumption of resources is also an important issue for emerging regional urban research [154]. Although consumption is better related directly to affluence, some government policies aim to shift economies from export to national consumption, and urbanization is a key mechanism to encourage consumption [155]. The number and size of households, whether they are localized or diffuse, what kinds of productive work they can engage in, and so on, are part of the consumption puzzle $[116,117,156]$. Urban mosaics are intimately involved in economies of consumption in many cases, and how the structure of one influences the structure of the other is a key research topic.

\section{Sustainability}

Here we link contemporary models of urban systems to sustainability. The intent is to survey ecological research frontiers that can contribute to sustainability goals. Conceiving of urbanization as an openended, non-linear, and multifaceted process meshes well with emerging conceptions of urban sustainability as a process or trajectory toward greater social, economic, and ecological integrity in citysuburban-exurban-rural systems [7]. Sustainability shares with urbanization the potential for non-linear changes, the feedback among related processes, the absence of a fixed end point, and influence of the four features of urbanization we have described. We propose links between sustainability and the four features to identify ecological research needs. 


\subsection{Complexity}

The spatial complexity of urban regional systems has several implications for sustainability. First, plans that do not consider the needs and opportunities for sustainability that originate in the entire city-suburban-exurban-rural regional system cannot provide a full accounting of what must be done or what has been accomplished through time. Both biophysical and social heterogeneity across the region play a role in achieving or thwarting sustainability goals [157]. Considering both social and biophysical heterogeneity together is also necessary to ensure that environmental heterogeneity and social inequities do not overlap in ways that result in environmental injustice.

Second, the spatial complexity of urban regional systems requires that the processes of change be understood. Acknowledging that some urban areas are growing in size and extent while others may be shrinking, and still others may not yet be urban, is a major step in fitting sustainability plans to features. Even more subtly, various processes of urban change may be differentially distributed across even a single urban megaregion. For example, sustainability plans that favor urban centers without concern for the social, environmental, and economic effects on villages elsewhere in the region may have less chance of succeeding than those that account for such changes [158].

A final caution that emerges from recognizing the spatial complexity of urban systems relates to inconspicuous processes. Myopic focus on the coarse scale structure of urban-rural complexes (e.g., Figure 3) may blind policy makers and researchers to the processes that underlie them, including inconspicuous processes, such as cultural dynamics and economic interdependencies. This myopia is especially likely for ecological processes, including primary production, decomposition, nutrient recycling, and the concentration or mitigation of contaminants [159]. The predominance of built infrastructure over green and blue infrastructure in many urban theories [160] also may lead policy makers and practitioners to neglect the biophysical processes and associated ecosystem services that affect sustainability [161].

\subsection{Connectivity}

Connectivity within and among regions is a hallmark of contemporary urbanization [20,162]. Sustainability policy and practice in one place must therefore consider inputs from other places. It is important to understand the environmental amenities, as well as any disamenities or hazards, associated with the different locations within a connected urban region. The influences of those features may spread well beyond their borders and affect the ability of regional or neighboring sustainability goals to be met [163]. Watershed management is an example of a situation in which different jurisdictions cooperate across boundaries on sustainability efforts, recognizing that the upstream and downstream zones are affected by water flow and the movement of organisms along riparian corridors.

An important characteristic of the fluxes among patches in an urban region is that only some are actively managed. Just as some patches are often neglected, such as vacant lots, tiny marginal parcels, or abandoned buildings [164], the flow of services such as groundwater recharge, and of hazards such as wildfire, from those sites also can be neglected $[165,166]$. Sustainability goals will be better served where entire urban-rural-wild mosaics and key fluxes among patches are understood [9]. 
The types and magnitudes of imported material and financial resources can influence the sustainability of a target urban area. Some of these imports will be intentional and some will be incidental or accidental. This connectivity means that the most ethical stances will consider the environmental, economic, and social effects of decisions and activities in a given urban system on cities, suburbs, rural, and wild areas far away.

Lifestyle and livelihood are key aspects of social-ecological systems that are affected by connectivity [84]. The adoption of cultural and lifestyle norms from elsewhere is common in contemporary urbanization. Where these affect patterns of consumption, land use, and environmental decision-making from households through formal government authorities, the effects on sustainability goals must be considered.

The connectivity among informal networks of a city is also important for sustainability. Technological innovation has given rise to the near-instantaneous transmission of information and signals among physically distant points. These increasingly important connections are effectively modeled as complex networks of interaction and influence. In particular, the components of interpersonal social networks - arising from telecommunications, the world wide web, email, social media, etc. - have a significant effect on human decision making and social dynamics in urban systems [167-169]. In addition, economic connectivity, such as the network of interdependencies between labor skills that emerge through a city's production activities [170], have been shown to constrain a city's ability to transition to a more green economy [171]. Thus these largely hidden connectivity networks will likely be a critical component of an emerging science of cities.

\subsection{Diffuseness}

Sustainability goals must take into account the magnitude and direction of human migrations. Circular, seasonal, or opportunistic migrations are notable causes of diffuseness in the global urban estate $[101,102,136]$. How those movements affect human capital, resource demands, and the use of different lands must be known to establish and monitor sustainability goals. The phenomenon of distributed households, with their implications for land use, consumption, and infrastructure, must also play a central role in sustainability plans. Studying the ecological impacts of such household structures is a key research need.

The diffuse patterns of governance that characterize most urban regions must be accommodated. In fact, some of these burgeoning governance arrangements are a response to the need for establishing and acting in more sustainable ways. Cross-boundary environmental compacts are an example. The diffuseness of governance is in some cases a boon to sustainability plans, but in other instances thwarts broad-scale efforts, as when urban or town planning is vested in the smallest political units. Even in cases where formal arrangements would seem to flow from a powerful and well-informed central authority, intervening governance and commercial activities may limit the effectiveness of top-down or regionally focused sustainability plans [129]. Matching governance arrangements with social, equity, environmental, and economic needs and opportunities at various locations and at various spatial and temporal scales is an active area of research and application [153]. 


\subsection{Diversity}

Sustainability goals must fit an ever-increasing array of urban forms, functions, and dynamics encountered across the globe. Although international consortia are in place for sharing information about sustainability goals, plans, and assessments (e.g., ICLEI [172]), there is little theorization on the relationship of sustainability to the diversity of styles, modes, and changes in urban areas. Almost certainly, a theory that matches sustainability with the diversity of urban forms and dynamics could have significant practical value. Issues to consider include shifting functions of urban areas or their districts, the existence of hazards and opportunities that emerge from regional or local conditions, the human demographics of urban change and migration, and the growing wealth gaps associated with urban change [173]. All these issues, and many more, make the success of a one-size-fits-all sustainability plan unlikely. The new global urban features, as acknowledged facts on the ground, suggest that localized sustainability solutions be sought, but always within their regional and global contexts. Furthermore, sustainability practices based on these features should be flexible and nimble enough to adapt to intraregional differences and needs.

\section{Conclusions}

We have examined the collective wisdom about contemporary global urban form and change in order to help advance ecological research and its application to sustainability. Cities have long been recognized as complex systems [174,175] and, since the mid 20th century especially, some cities have been identified as part of extensive regional agglomerations. Yet the ecological science of cities has not articulated an inclusive theory, nor has it fully risen to the challenge of informing sustainability goals and plans. Contributing to both urban ecological theory and its application to sustainability practice, we have identified from the literature four inextricably linked features that characterize contemporary urban systems: complexity, connectedness, diffuseness, and diversity. Just as changing notions of sustainability have allowed us to see that goal as complex, non-linear, and ever evolving [7], so too the conception of urbanization as measurable progress toward an industrial or service based steady state must be replaced by one that is more process-based, open-ended, and applicable to emerging urban systems [1].

These four features of contemporary urbanization broadly encompass many of the theories and models of urbanization we have encountered, and mesh well with trajectory-based conceptions of sustainability. Thus, they may frame a still larger and more inclusive, but yet to be finalized, theory of contemporary urbanization that provides a home for different kinds of models and suggests key contrasts along which comparisons may be made. Sustainability goals, plans, and assessments must account for the structures, functions, and classifications suggested by these four features. Sustainability must be conceived of and pursued as a process that mirrors the complexity, connectivity, diffuseness, and diversity of urban regions that exist and are emerging anew around the world.

\section{Acknowledgments}

The authors of this paper are members of the Urban Sustainability Research Coordination Network that is supported by the U.S. National Science Foundation (NSF) through Grant No. 1140070. 
Additional support has been provided by the NSF to DLC and DMI through the CAP LTER Program (Grant No. 1026865) and to STAP through the BES LTER Program (Grant No. 1027188). MRM, GRH and MNP were also supported by NSF BCS-0948229. OB was funded by FONDECYT\#11110183, FONDAP \#1510020 and CONICYT PFB-23.

\section{Author Contribution}

Melissa R. McHale and Steward T.A. Pickett led the collaborative efforts to produce this publication. All authors contributed substantially to the ideas, concepts, and work presented in this paper. All authors were also involved in the preparation of the manuscript and have approved the submitted form.

\section{Conflicts of Interest}

The authors declare no conflict of interest.

\section{References}

1. McHale, M.R.; Bunn, D.N.; Pickett, S.T.A.; Twine, W. Urban ecology in a developing world: How advanced socio-ecological theory needs Africa. Front. Ecol. Environ. 2013, 11, 556-564.

2. Angel, S.; Parent, J.; Civco, D.L.; Blei, A.; Potere, D. The dimensions of global urban expansion: Estimates and projections for all countries. Prog. Plan. 2011, 75, 53-107.

3. Forman, R.T.T.; Godron, M. Landscape Ecology; John Wiley and Sons: New York, NY, USA, 1986; pp. 1-619.

4. Marcotullio, P.J.; Solecki, W. What is a city? An essential definition for sustainability. In Urbanization and Sustainability: Linking Urban Ecology, Environmental Justice, and Environmental Change; Boone, C.G., Fragkias, M., Eds.; Springer: New York, NY, USA, 2013; pp. 11-25.

5. Larondelle, N.; Hamstead, Z.A.; Kremer, P.; Haase, D.; McPhearson, T. Applying a novel urban structure classification to compare the relationships of urban structure and surface temperature in Berlin and New York City. Appl. Geogr. 2014, 53, 427-437.

6. Alvesson, M.; Sandberg, J. Generating research questions through problematization. Acad. Manag. Rev. 2011, 36, 247-271.

7. Childers, D.L.; Pickett, S.T.A.; Grove, J.M.; Ogden, L.; Whitmer, A. Advancing urban sustainability theory and action: Challenges and opportunities. Landsc. Urban Plan. 2014, 125, 320-328.

8. Melosi, M.V. The Sanitary City: Urban Infrastructure in America from Colonial Times to the Present; Johns Hopkins University Press: Baltimore, MD, USA, 2000; p. 600.

9. McGrath, B.; Pickett, S.T.A. The metacity: A conceptual framework for integrating ecology and urban design. Challenges 2011, 2011, 55-72.

10. Parker, S. Urban Theory and the Urban Experience: Encountering the City; Routledge: New York, NY, USA, 2004; p. 210.

11. Haase, D.; Bernt, M.; Grossman, K.; Mykhnenko, V.; Rink, D. Varieties of shrinkage in European cities. Eur. Urban Reg. Stud. 2013, doi:10.1177/0969776413481985. 
12. Harvey, D. Justice, Nature and the Geography of Difference; Basil Blackwell: Oxford, UK, 1996.

13. Soja, E.W. Postmetropolis; Oxford University Press: Blackwell, UK, 2000.

14. Simone, A. City Life from Jakarta to Dakar: Movements at the Crossroads; Routledge: New York, NY, USA, 2010.

15. Smith, M.E. The role of ancient cities in research on contemporary urbanization. Urban. Glob. Environ. Change 2012, 8, 15-19.

16. Johnson, E.A. Succession, an unfinished revolution. Ecology 1979, 60, 238-240.

17. Pickett, S.T.A.; Meiners, S.J.; Cadenasso, M.L. Domain and propositins of succession theory. In Theory of ecology; Scheiner, S.M., Willig, M.R., Eds. University of Chicago Press: Chicago, IL, USA, 2011.

18. Meiners, S.J.; Pickett, S.T.A.; Cadenasso, M.L. An Integrative Approach to Successional Dynamics: Tempo and Mode of Vegetation Change; Cambridge University Press: New York, NY, USA, 2015.

19. Light, J.S. The Nature of Cities: Ecological Visions and the American Urban Professions 1920-1960; Johns Hopkins University Press: Baltimore, MD, USA, 2009.

20. Seto, K.C.; Reenberg, A.; Boone, C.G.; Fragkias, M.; Haase, D.; Langanke, T.; Marcotullio, P.; Munroe, D.K.; Olah, B.; Simon, D. Urban land teleconnections and sustainability. Proc. Natl. Acad. Sci. USA 2012, 109, 7687-7692.

21. Knox, P. Atlas of Cities; Princeton University Press: Princeton, NJ, USA, 2014; p. 255.

22. Bai, X.; McAllister, R.R.J.; Beaty, R.M.; Taylor, B. Urban policy and governance in a global environment: Complex systems, scale mismatches and public participation. Curr. Opin. Environ. Sustain. 2010, 2, 129-135.

23. Williams, R. The Country and the City; Oxford University Press: New York, NY, USA, 1975.

24. Green, N. The Spectacle of Nature: Landscape and Bourgeois Culture in Nineteenth-Century France; Manchester University Press: Manchester, UK, 1990.

25. Bettencourt, L.; West, G. A unified theory of urban living. Nature 2010, 467, 912-913.

26. Bettencourt, L. The origins of scaling in cities. Science 2013, 340, 1438-1441.

27. Lynch, K. Good City Form; MIT Press: Cambridge, MA, USA, 1981; p. 512.

28. Pope, A. Ladders; Princeton Architectural Publishers: New York, NY, USA, 1997.

29. Marshall, S. Streets and Patterns; Spon Press: New York, NY, USA, 2005; p. 312.

30. Strano, E.; Nicosia, V.; Latora, V.; Porta, S.; Barthélemy, M. Elementary processes governing the evolution of road networks. Sci. Rep. 2012, 2, 296.

31. Louf, R.; Barthelemy, M. A typology of street patterns. J. R. Soc. Interface 2014, 11, 20140924.

32. Shane, D.G. Recombinant Urbanism: Conceptual Modeling in Architecture, Urban Design, and City Theory; John Wiley \& Sons: Hoboken, NJ, USA, 2005; p. 344.

33. Foucault, M. The Order of Things: An Archeology of the Human Sciences; Vintage Books: New York, NY, USA, 1971; p. 387.

34. Harris, C.D. A functional classification of cities in the United States. Geogr. Rev. 1943, 33, 86-99.

35. Pickett, S.T.A.; McGrath, B.; Cadenasso, M.L.; Felson, A.J. Ecological resilience and resilient cities. Build. Res. Inf. 2014, 42, 143-157.

36. Gandy, M. Rethinking urban metabolism: Water, space and the modern city. City 2004, 8, 363-379. 
37. Grove, J.M.; Burch, W.R.; Wilson, M.; Vemuri, A.W. The mutual dependence of social meanings, social capital, and the design of urban green infrastructure. In Designing Patch Dynamics; McGrath, B., Marshall, V., Cadenasso, M.L., Grove, J.M., Pickett, S.T.A., Plunz, R., Towers, J., Eds.; Columbia, Graduate School of Architecture, Planning, and Preservation: New York, NY, USA, 2007; Volume New Urbanisms 10, pp. 66-77.

38. Kupel, D.E. Investigating urban infrastructure. J. Urban Hist. 2001, 27, 520-525.

39. Machlis, G.E.; Force, J.E.; Burch, W.R. The human ecosystem. 1. The human ecosystem as an organizing concept in ecosystem management. Soc. Nat. Resour. 1997, 10, 347-367.

40. Lefebvre, H. The Production of Space; Blackwell: Oxford, UK, 1991; p. 454.

41. Millennium Ecosystem Assessment. Ecosystems and Human Well-Being: A Framework for Assessment; Island Press: Washington, DC, USA, 2003; pp. 1-245.

42. Robbins, P. Political Ecology: A Critical Introduction; Blackwell Publishing: Malden, MA, USA, 2004; p. 242.

43. Walker, P.A. Political ecology: Where is the ecology? Prog. Hum. Geogr. 2005, 29, 73-82.

44. Alonso, W. Location and Land Use: Toward a General Theory of Land Rent; Harvard University Press: New York, NY, USA, 1964.

45. Irwin, E.G.; Jayaprakash, C.; Munroe, D.K. Towards a comprehensive framework for modeling urban spatial dynamics. Landsc. Ecol. 2009, 24, 1223-1236.

46. Firey, W. Man, Mind and Land: Theory of Resource Use; The Free Press: Glencoe, IL, USA, 1960; p. 256.

47. Storper, M.; Manville, M. Behavior, preferences and cities: Urban theory and urban resurgence. Urban Stud. 2006, 43, 1247-1274.

48. Grove, J.M.; Locke, D.H.; O’Neil-Dunne, J.P.M. An ecology of prestige in New York City: Examining the relationships among population density, socio-economic status, group identity, and residential canopy cover. J. Environ. Manag. 2014, 54, 401-419.

49. Dear, M.; Flusty, S. Postmodern urbanism. Ann. Assoc. Am. Geogr. 1998, 88, 50-72.

50. Harvey, D. Spaces of Hope; University of California Press: Berkeley, CA, USA, 2000; p. 1-293.

51. Dillon, M. Introduction to Sociological Theory: Theorists, Concepts, and Their Applicability to the Twenty-First Century, 2nd ed.; Wiley Blackwell: Malden, MA, USA, 2014.

52. Sassen, S. Cities in a World Economy, 4th ed.; Sage: Washington, DC, USA, 2012; p. 399.

53. Thierstein, A.; Förster, A. The Image and the Region: Making Mega-City Regions Visible! Lars Müller Publishers: Baden, Switzerland, 2008.

54. Pincetl, S. From the sanitary to the sustainable city: Challenges to institutionalizing biogenic (nature's services) infrastructure. Local Environ. 2010, 15, 43-58.

55. Wirth, L. Human ecology. Am. J. Sociol. 1945, 50, 483-488.

56. Glaeser, E. Triumph of the City: How Our Greatest Invention Makes us Richer, Smarter, Greener, Healthier, And Happier; Penguin Press: New York, NY, USA, 2011.

57. Smith, N. New globalism, new urbanism: Gentrification as global urban strategy. Antipode 2002, 34, 434-457.

58. Brenner, N. Beyond state-centrism? Space, territoriality, and geographic scale in globalization studies. Theory Soc. 1999, 28, 39-78. 
59. Damm, J. The internet and the fragmentation of Chinese society. Crit. Asian Stud. 2007, 39, 273-294.

60. Graham, S.; Marvin, S. Telecommunications and the City: Electronic Spaces, Urban Places; Routledge: London, UK, 1996.

61. Rees, W.E. Eco-footprint analysis: Merits and brickbats. Ecol. Econ. 2000, 32, 371-374.

62. Cronon, W. Nature's Metropolis: Chicago and the Great West; Norton: New York, NY, USA, 1991.

63. Gottmann, J. Megalopolis: The Urbanized Northeastern Seaboard of the United States; The Twentieth Century Fund: New York, NY, USA, 1961.

64. Hall, P. Looking backward, looking forward: The city region of the Mid-21st century. Reg. Stud. 2009, 43, 803-817.

65. Harrison, J.; Hoyler, M. Megaregions. Globalization's New Urban Form? Edward Elgar: London, UK, 2014.

66. Laband, D.N.; Lockaby, B.G.; Zipperer, W.C. Urban.-Rural Interfaces: Linking People and Nature; American Society of Agronomy, Crop Science Society of America, and Soil Science Society of America: Madison, WI, USA, 2012.

67. Regional Plan Association. Northeast Megaregion 2050: A Common Future; Regional Plan Association: New York, NY, USA, 2007.

68. Fang, S.; Gertner, G.Z.; Sun, Z.; Anderson, A.A. The impact of interactions in spatial simulation of the dynamics of urban sprawl. Landsc. Urban Plan. 2005, 73, 294-306.

69. Yang, J.; Song, G.; Kin, J. Measuring Spatial Structure of China's Mega-Regions; Lincoln Institute of Land Policy: Cambridge, MA, USA, 2012; p. 19.

70. Metaxas, T.; Tsavdariou, M. From "blue banana" to "red octopus" and the development of Eastern and Southern Eurpean cities: Warsaw and Lisbon. Reg. Sect. Econ. Stud. 2013, 13, 15-31.

71. UN Habitat. State of the world's Cities: Prosperity; United Nations: New York, NY, USA, 2012; p. 152.

72. Forman, R.T.T. Urban Regions: Ecology and Planning beyond the City. Cambridge University Press: New York, NY, USA, 2008.

73. Pickett, S.T.A.; Cadenasso, M.L. Landscape ecology: Spatial heterogeneity in ecological systems. Science 1995, 269, 331-334.

74. Cadenasso, M.L.; Pickett, S.T.A.; Schwarz, K. Spatial heterogeneity in urban ecosystems: Reconceptualizing land cover and a framework for classification. Front. Ecol. Environ. 2007, 5, 80-88.

75. Bormann, F.H.; Likens, G.E. Patterns and Processes in a Forested Ecosystem; Wiley and Sons: New York, NY, USA, 1979; p. 253.

76. Turner, M.G. Landscape ecology: The effect of pattern on process. Ann. Rev. Ecol. Syst. 1989, 20, 171-197.

77. Luck, M.; Wu, J. A gradient analysis of urban landscape pattern: A case study from the Phoenix metropolitan region, Arizona, USA. Landsc. Ecol. 2002, 17, 327-339.

78. Grimm, N.B.; Grove, J.M.; Pickett, S.T.A.; Redman, C.L. Integrated approaches to long-term studies of urban ecological systems. BioScience 2000, 50, 571-584. 
79. Pickett, S.T.A.; Cadenasso, M.L.; Grove, J.M.; Groffman, P.M.; Band, L.E.; Boone, C.G.; Burch, W.R.; Grimmond, C.S.B.; Hom, J.; Jenkins, J.C.; et al. Beyond urban legends: Emerging framework of urban ecology, as illustrated by the Baltimore Ecosystem Study. BioScience 2008, $58,141-152$.

80. Collins, S.L.; Carpenter, S.R.; Swinton, S.M.; Orenstein, D.E.; Childers, D.L.; Gragson, T.L.; Grimm, N.B.; Grove, J.M.; Harlan, S.L.; Kaye, J.P.; et al. An integrated conceptual framework for long-term social-ecological research. Front. Ecol. Environ. 2011, 9, 351-357.

81. Pickett, S.T.A.; Burch, W.R., Jr.; Dalton, S.D.; Foresman, T.W. Integrated urban ecosystem research. Urban Ecosyst. 1997, 1, 183-184.

82. McDonnell, M.J.; Breuste, J.; Hahs, A. Introduction: Scope of the book and need for developing a comparative approach to the ecology of cities and towns. In Ecology of Cities and Towns: A Comparative Approach; McDonnell, M.J., Hahs, A., Breuste, J., Eds.; Cambridge University Press: New York, NY, USA, 2009; pp. 1-5.

83. Pickett, S.T.A.; White, P.S. The Ecology of Natural Disturbance and Patch Dynamics; Academic Press: Orlando, FL, USA, 1985; pp. 1-472.

84. Boone, C.G.; Redman, C.L.; Blanco, H.; Haase, D.; Koch, J.; Lwasa, S.; Nagendra, H.; Pauleit, S.; Pickett, S.T.A.; Seto, K.C.; et al. Reconceptualizing land for sustainable urbanity. In Rethinking Urban Land Use in a Global Era; Seto, K.C., Reenberg, A., Eds.; MIT Press: Cambridge, MA, USA, 2014; pp. 313-330.

85. Gunderson, L.H.; Holling, C.S. Panarchy: Understanding Transformations in Human and Natural Systems; Island Press: Washington, DC, USA, 2002; p. 507.

86. Pickett, S.T.A.; Cadenasso, M.L.; McGrath, B. Resilience in Ecology and Urban Design: Linking Theory and Practice for Sustainable Cities; Springer: New York, NY, USA, 2013; p. 499.

87. Kaye, J.P.; Groffman, P.M.; Grimm, N.B.; Baker, L.A.; Pouyat, R.V. A distinct urban biogeochemistry? Trends Ecol. Evol. 2006, 21, 192-199.

88. Kennedy, C.; Pincetl, S.; Bunje, P. The study of urban metabolism and its application to urban planning and design. Environ. Pollut. 2011, 159, 1965-1973.

89. Foster, J.B. Marx's theory of metabolic rift: Classical foundations for environmental sociology. Am. J. Sociol. 1999, 105, 366-405.

90. Strobach, M.W.; Warren, P.S.; Peterson, M.N. Urban wildlife science in coupled human-natural systems. In Urban Wildlife Conservation: Theory and Practice; McCleery, R.A., Moorman, C., Peterson, M.N., Eds.; Springer: New York, NY, USA, 2014; pp. 33-53.

91. Yamamoto, A.T.; Nadaraja, M. Urban Crisis: Culture and the Sustainability of Cities; United Nations University: Tokyo, Japan, 2006.

92. Gelfand, M.J.; Raver, J.L.; Nishii, L.; Leslie, L.M.; Lun, J.; Lim, B.C.; Duan, L.; Almaliach, A.; Ang, S.; Arnadottir, J.; et al. Differences between tight and loose cultures: A 33-nation study. Science 2011, 332, 1100-1104.

93. Samet, R.H. Complexity, the science of cities and long-range futures. Futures 2013, 47, 49-58.

94. Terkenli, T.S. New landscape spatialities: The changing scales of function and symbolism. Landsc. Urban Plan. 2005, 70, 165-176.

95. Qubbaj, M.; Shutters, S.T.; Muneepeerakul, R. Living in a netowrk of scaling cities and finite resources. Bull. Math. Biol. 2014, 77, 390-407. 
96. Metzger, A.; McHale, M.R.; Hess, G.H.; Steelman, T. The urban metabolism of three rapidly growing cities in North Carolina's Research Triangle. Urban Ecosyst. 2015, submitted.

97. Soja, E.W. Postmodern Geographies; Verso: London, UK, 1989; p. 266.

98. Cresswell, T. Mobility in the Modern Western World; Routledge: New York, NY, USA, 2006.

99. Drake, D. Wildlife damage management in the urban landscape. In Urban Wildlife Conservation: Theory and Practice; McCleery, R.A., Moorman, C., Peterson, M.N., Eds.; Springer: New York, NY, USA, 2014; pp. 389-401.

100. Spiegel, A.; Watson, V.; Wilkinson, P. Domestic diversity and fluidity among some African households in greater Cape Town. Soc. Dyn. 1996, 22, 7-30.

101. Collinson, M.; Tollman, S.M.; Kahn, C.S.; Garenne, M. Highly prevalent circular migration: Households, mobility and economic status in rural South Africa. In African on the Move: African Migration and Urbansation in Comparative Perpsective; Tienda, M., Fildley, S.E., Tollman, S., Eds.; Wits University Press: Johannesburg, South Africa, 2006; pp. 194-216.

102. Myers, G.A. African Cities: Alternative Visions of Urban Theory and Practice; Zed Books: New York, NY, USA, 2011.

103. Dufour, D.L.; Piperata, B.A. Rural-to-urban migration in Latin America: An update and thoughts on the model. Am. J. Hum. Biol. 2004, 16, 395-404.

104. Padoch, C.; Brondizio, E.; Costa, S.; Pinedo-Vasquez, M.; Sears, R.R.; Siqueira, A. Urban forest and rural cities: Multi-sited households, consumption patterns, and forest resources in Amazonia. Ecol. Soc. 2008, 13, Article 2.

105. Seto, K.C.; de Groot, R.; Bringezu, S.; Erb, K.; Graedel, T.E.; Ramankutty, N.; Reenberg, A.; Schmitz, O.J.; Skole, D.L. Stocks, flows, and prospects of land. In Linkages of Sustainability; Graedel, T.E., van der Voet, E., Eds.; MIT Press: Cambridge, MA, USA, 2010; pp. 72-96.

106. Comaroff, J.L.; Comaroff, J. Ethnicity, Inc.; University of Chicago Press: Chicago, IL, USA, 2009.

107. Plowright, R.K.; Field, H.E.; Smith, C.; Divljan, A.; Palmer, C.; Tabor, G.; Daszak, P.; Foley, J.E. Reproduction and nutritional stress are risk factors for Hendra virus infection in little red flying foxes (Pteropus scapulatus). Proc. R. Soc. B Biol. Sci. 2008, 275, 861-869.

108. Plowright, R.K.; Foley, P.; Field, H.E.; Dobson, A.P.; Foley, J.E.; Eby, P.; Daszak, P. Urban habituation, ecological connectivity and epidemic dampening: The emergence of Hendra virus from flying foxes (Pteropus spp.). Proc. R. Soc. B Biol. Sci. 2011, 278, 3703-3712.

109. Shane, D.G. Urban Design since 1945-A Global Perspective; John Wiley \& Sons, Ltd: Chichester, UK, 2011; p. 360.

110. Derudder, B.; Taylor, P. The cliquishness of world cities. Glob. Netw. 2005, 5, 71-91.

111. Beaverstock, J.V.; Smith, R.G.; Taylor, P.J. World-city network: A new metageography. Ann. Assoc. Am. Geogr. 2000, 90, 123-134.

112. Choi, J.H.; Barnett, G.A.; Chon, B.-S. Comparing world city networks: A network analysis of Internet backbone and aire transport intercity linkages. Glob. Netw. 2006, 6, 81-99.

113. Levins, R. Some demographic and genetic consequences of environmental heterogeneity for biological control. Bull. Entomol. Soc. Am. 1969, 15, 237-240.

114. Hanski, I. Habitat connectivity, habitat continuity, and metapopulations in dynamic landscapes. Oikos 1999, 87, 209-219. 
115. Liu, J.; An, L.; Batie, S.S.; Bearer, S.L.; Chen, X.; Gropp, R.E.; He, G.; Liang, Z.; Linderman, M.A.; Mertig, A.G.; et al. Beyond population size: Examining intricate interactions among population structure, land use, and environment in Wolong Nature Reserve, China. In Population, Land Use, and Environment; National Academies Press: Washington, DC, USA, 2005; pp. 217-237.

116. Liu, J.; Daily, G.C.; Ehrlich, P.R.; Luck, G.W. Effects of household dynamics on resource consumption and biodiversity. Nature 2003, 1359, 1-3.

117. Peterson, M.N.; Peterson, T.; Liu, J. The Housing Bomb: Why Our Addiction to Houses is Destroying the Environment and Threatening Society; Johns Hopkins University Press: Baltimore, MD, USA, 2013.

118. Castells, M. The Rise of the Network Society: The Information Age: Economy, Society, and Culture; John Wiley \& Sons: London, UK, 2011; Volume 1.

119. Appadurai, A. Modernity at Large: Cultural Dimensions of Globalization; University of Minnesota Press: Minneapolis, MN, USA, 1996.

120. Schoon, M.L. Governance in Southern African transboundary protected areas. In Parks, Peace, and Partnerships; Quinn, M., Broberg, L., Freimund, W., Eds.; University of Calgary Press: Calgary, AB, Canada, 2012.

121. Schoon, M.L. Governance structures in transboundary conservation: How institutional evolution influences cross-border cooperation. Conserv. Soc. 2013, 11, 420-428.

122. Andersson, J.A.; de Garine-Wichatitasky, M.; Cumming, D.H.M.; Dzingirai, V.; Giller, K.E. Transfrontier Conservation Areas: People Living on the Edge; Routledge: New York, NY, USA, 2013.

123. Büscher, B. Transforming the Frontier: Peace Parks and the Politics of Neoliberal Conservation in Southern Africa; Duke University Press: Durham, UK, 2013.

124. Svendsen, E. Storyline and design: How civic stewardship shapes urban design in New York City. In Resilience in Ecology and Urban Design: Linking Theory and Practice for Sustainable Cities; Pickett, S.T.A., Cadenasso, M.L., McGrath, B., Eds.; Springer: New York, NY, USA, 2013; pp. 269-287.

125. Andersson, C.; Törnberg, A.; Törnberg, P. Societal systems-Complex or worse? Futures 2014, $63,145-157$.

126. Douglass, M. The World of Goods: Towards an Anthropology of Consumptio; Rougledge: London, UK, 1996.

127. Low, S.M. The anthropology of cities: Imagining and theorizing the city. Ann. Rev. Anthropol. 1996, 25, 383-409.

128. Smith, N.; Caris, P.; Wyly, E. The Camden syndrome and the menace of suburban decline: Residential disinvestment and the discontents of Camden County, New Jersey. Urban Aff. Rev. 2001, 36, 497-531.

129. Miller, T. China's Urban Billion: The Story behind the Biggest Migraion in Human History; Zed Books: New York, NY, USA, 2012.

130. Lwasa, S. Planning innovation for better urban communities in sub-Saharan Africa: The educational challenge and potential responses. Town Reg. Plan. 2013, 60, 38-48. 
131. Lomnitz, L.A. Informal exchange networks in formal systems: A theoretical model. Am. Anthropol. 1988, 90, 42-55.

132. Rademacher, A. Reigning the River: Urban Ecologies and Political Transformation in Kathmandu; Duke University Press: Durham, UK, 2011.

133. Barbosa, O.; Villagra, P. Socio-ecological studies in urban and rural ecosystems in Chile. In Earth Stewardship: Linking Ecology and Ethics in Theory and Praxis; Rozzi, R., Chapin, S.F., Callicott, J.B., Pickett, S.T.A., Power, M., Armesto, J.J., May, R.H., Jr., Eds.; Springer: New York, NY, USA, 2015; pp. 297-311.

134. Davis, M. Planet of Slums; Verso: London, UK, 2006.

135. Koolhaas, R. Fragments of a lecture on Lagos. In Under Siege: Four African Cities. Freetown, Johannesburg, Kinshasa, Lagos; Enewzor, O., Basualdo, C., Bauer, U.M., Ghez, S., Maharaj, S., Nash, M., Zaya, O., Eds.; Hartje Cantz Publishers: Ostfildern-Ruit, Germany, 2002.

136. Simone, A. For the City yet to Come: Changing African Life in Four Cities; Duke University Press: Durham, UK, 2004.

137. Appadurai, A. Deep democracy: Urban governmentality and the horizon of politics. Environ. Urban. 2001, 13, 24-43.

138. United Nations. Urbanization: Mega \& metacities, new city states. In UN-Habitat: State of the world's Cities 2006/7; United Nations: Nairobi, Kenya, 2007.

139. Somers, M. Invading Rio's Rocinha. Photo ${ }^{\odot}$ matteo0702. Licensed by the Creative Commons. Available online http://moon.com/2011/11/invading-rios-rocinha/ (accessed on 19 April 2015).

140. Van Dijk, B. Ordos DSC_0045. Licensed by the Creative Commons. Available online: https://www.flickr.com/photos/zilpho/sets/72157629283308739 (accessed on 19 April 2015).

141. 1Droid Jamlos. City-Skyline Houston. Licensed by the Creative Commons. Available online: https://www.flickr.com/photos/jamlos/2734415645/ (accessed on 19 April 2015).

142. Debatty, R. World Changing. Photo (C) unknown. Forgotten Detroit. Licensed by the Creative Commons. Available online: http://www.worldchanging.com/archives/007999.html (accessed on 19 April 2015).

143. Grimm, N.B.; Faeth, S.H.; Golubiewski, N.E.; Redman, C.L.; Wu, J.; Bai, X.; Briggs, J.M. Global change and the ecology of cities. Science 2008, 319, 756-760.

144. McDonnell, M.J.; Hahs, A. Comparative ecology of cities and towns: Past, present and future. In Ecology of Cities and Towns: A Comparative Approach; McDonnell, M.J., Hahs, A., Breuste, J., Eds.; Cambridge University Press: New York, NY, USA, 2009; pp. 71-89.

145. Research Center for Eco-Enviromental Sciences, Chinese Academy of Sciences. Available online: http://english.rcees.cas.cn/rh/ss/ssbuers/ (accessed on 19 April 2015).

146. Wu, J.; Wei-Ning, X.; Jingzhu, Z. Urban Ecology in China: Historical developments and future directions. Landsc. Urban Plan. 2014, 125, 222-233.

147. African Center for Cities. Available online: http://africancentreforcities.net (accessed on 19 April 2015).

148. South African Environmental Observation Network. Available online: http://www.saeon.ac.za (accessed on 19 April 2015).

149. Central Arizona Long-Term Ecological Research. Available online: https://caplter.asu.edu/ (accessed on 19 April 2015). 
150. Baltimore Ecosystem Study. Available online: http://beslter.org/ (accessed on 19 April 2015).

151. Hahs, A.; McDonnell, M.J.; Breuste, J. A comparative ecology of cities and towns: Synthesis of opportunities and limitations. In Ecology of Cities and Towns: A Comparative Approach; McDonnell, M.J., Hahs, A., Breuste, J., Eds.; Cambridge University Press: New York, NY, USA, 2009; pp. 574-596.

152. Zellmer, A.J.; Allen, T.F.H.; Kesseboehmer, K. The nature of ecological complexity. Ecol. Complex. 2006, 3, 171-182.

153. Connolly, J.J.T.; Pickett, S.T.A.; Boone, C.G.; Fisher, D.R.; Hutyra, L.R.; Raciti, S.M.; Wolheim, W.M.; Kaushal, S.S.; Oneil-Dunne, J.; Grove, J.M.; et al. Emerging social and environmental challenges in urbanizing megaregions. Urban Ecosyst. 2015, submitted.

154. Satterthwaite, D. How urban societies can adapt to resource shortage and climate change. Philoso. Trans. R. Soc. A 2011, 369, 1762-1783.

155. Normile, D. China's living laboratory in urbanization. Science 2008, 319, 740-743.

156. Liu, Q.; Brakenhielm, S. Variability of plant species diversity in Swedish natural forest and its relation to atmospheric deposition. Vegetatio 1996, 125, 63-72.

157. Pickett, S.T.A.; Boone, C.G.; McGrath, B.P.; Cadenasso, M.L.; Childers, D.L.; Ogden, L.A.; McHale, M.; Grove, J.M. Ecological science and transformation to the sustainable city. Cities 2013, 32, S10-S20.

158. Ye, X. China's urban-rural integration policies. J. Curr. Chin. Aff. 2009, 4, 117-143.

159. Spirn, A.W. The Granite Garden: Urban Nature and Human Design; Basic Books: New York, NY, USA, 1984; p. 1-334.

160. Gandy, M. Concrete and Clay: Reworking Nature in New York City; MIT Press: Cambridge, MA, USA, 2003; p. 344.

161. Childers, D.; Cadenasso, M.L.; Grove, J.M.; Marshall, V.; McGrath, B.; Pickett, S.T.A. An ecology for cities: A transformational nexus of design and ecology to advance climate change resilience and urban sustainability. Sustainability 2015, 7, 3774-3791.

162. Seto, K.; Reenberg, A. Rethinking Global Land Use in an Urban Era; MIT Press: Cambridge, MA, USA, 2014.

163. Pickett, S.T.A.; McGrath, B.; Cadenasso, M.L. The ecology of the metacity: Shaping the dynamic; patchy, networked, and adaptive cities of the future. In Resilience in Ecology and Urban Design: Linking Theory and Practice for Sustainable Cities; Pickett, S.T.A., Cadenasso, M.L., McGrath, B., Eds.; Springer: New York, NY, USA, 2013; pp. 463-489.

164. Kremer, P.; Hamstead, Z.A.; McPhearson, T. A social-ecological assessment of vacant lots in New York City. Landsc. Urban Plan. 2013, 120, 218-233.

165. Pickett, S.T.A. The wild and the city. In State of the Wild: A Global Portrait 2010; Redford, K.H., Fearn, E., Eds.; Island Press: Washington, DC, USA, 2010; pp. 153-159.

166. McPhearson, T.; Kremer, P.; Hamstead, Z.A. Mapping ecosystem services in New York City: Applying a social-ecological approach in urban vacant land. Ecosyst. Ser. 2013, 2013, 11-26.

167. Graham, S.; Aurigi, A. Virtual cities, social polarization, and the crisis in urban public space. J. Urban Technol. 1997, 4, 19-52.

168. Kotler, P. Reinventing marketing to manage the environmental imperative. J. Mark. 2011, 75, 132-135. 
169. Hanna, R.; Rohm, A.; Crittenden, V.L. We're all connected: The power of the social media ecosystem. Bus. Horiz. 2011, 54, 265-273.

170. Muneepeerakul, R.; Lobo, J.; Shutters, S.T.; Gomez-Lievano, A.; Qubbaj, M. Urban economies and occupation space: Can they get "there" from "here"? PLoS ONE 2013, 8, e73676.

171. Shutters, S.T.; Muneepeerakul, R.; Lobo, J. How hard is it for urban economies to become "green"? Environ. Plan. B Plan. Des. 2015, in press.

172. ICLEI Local Governments for Sustainability. Available online http://www.iclei.org (accessed on 19 April 2015).

173. International Labour Organization. Global Employment Trends 2014; International Labour Office, United Nations: Geneva, Switzerland, 2014; p. 127.

174. Jacobs, J. The Death and Life of Great American Cities: The Failure of Town Planning; Random House: New York, NY, USA, 1961; pp. 1-458.

175. Berry, B.J.L. A new urban ecology? Urban Geogr. 2001, 22, 699-701.

(C) 2015 by the authors; licensee MDPI, Basel, Switzerland. This article is an open access article distributed under the terms and conditions of the Creative Commons Attribution license (http://creativecommons.org/licenses/by/4.0/). 